\title{
EDITAR A GÓNGORA CON INSTRUMENTOS DIGITALES: BASES METODOLÓGICAS Y PERSPECTIVAS TEÓRICAS PARA UN HIPERTEXTO DE LA POLÉMICA GONGORINA
}

\section{EDITING GÓNGORA WITH DIGITAL DEVICES: METHODOLOGICAL BASIS AND THEORETICAL APPROACHES OF AN HYPERTEXT OF GÓNGORA'S CONTROVERSY}

\author{
Sara Pezzini \\ Université Paris Sorbonne-OBVIL \\ sarpezzini@gmail.com \\ Héctor Ruiz Soto \\ Université Paris Sorbonne-OBVIL \\ hector.ruiz.soto@gmail.com
}

\begin{abstract}
Resumen
El artículo presenta el trabajo editorial del proyecto Góngora del Labex OBVIL (http://obvil.paris-sorbonne.fr/projets/edition-digitale-et-etude-de-la-polemique-autour-degongora) llevado a cabo entre 2013 y 2016 . Este proyecto publica una edición digital de la obra completa de Luis de Góngora y de la polémica de su recepción durante el siglo XVII. Para este cometido, la complementariedad entre la Filología tradicional y las Humanidades Digitales es un requisito que se traduce en una reflexión metodológica sobre la edición científica digital. Sobre esa base, el artículo hace hincapié en la construcción de un hipertexto que conecte a Góngora con su polémica a través del marcado XML de hipervínculos. Presenta dos proyectos de hipertextos en desarrollo a partir de ontologías y análisis de redes, que abren
\end{abstract}


pistas teóricas sobre la lectura web y las novedades que las Humanidades Digitales aportan al estudio de la obra de Góngora y de su recepción.

Palabras clave: Edición digital. Polémica gongorina. Hipertexto. Intertextualidad. Hipervínculo.

\begin{abstract}
This article presents the editorial work of the Góngora project of Labex OBVIL between 2013 and 2016. Its aim is to publish a digital edition of the complete works of Luis de Góngora and the controversy of his reception during the $\mathrm{XVII}^{\text {th }}$ century. In order to do so, the project attempted to enhance the complementarity of digital humanities and traditional academic edition and this led it to a reflection upon the methodology of the academic digital edition. Upon that basis, the study focuses on the construction of a hypertext connecting Góngora with its polemical reception through an XML markup of hyperlinks. This work presents two projects about hypertext that are now in working progress. These projects work with ontologies and computational network analysis that let us pose questions about how we read on the web and how Digital Humanities can enhance the study of Góngora's poetry and reception.
\end{abstract}

Keywords: Digital Edition. Góngora Controversy. Hypertext. Intertextuality. Hyperlink.

\title{
1. INTRODUCCIÓN ${ }^{1}$
}

En el año 1612 [Góngora] escribe y publica en Madrid sus dos poemas más extensos e importantes: el Polifemo y las Soledades. No pueden ustedes imaginar nada más divertido que la guerra despertada en el mundo literario por esos dos poemas.

Todos los escritores se dividieron en dos campos, absolutamente irreductibles. Alrededor de las obras de Góngora empezó a crecer, lo mismo que una hiedra frondosa, toda una serie de literatura de comentarios, de defensas, de ataques, en los que se mezclaban las doctrinas poéticas y los insultos personales (Salinas, 2007: 479).

En una conferencia pronunciada en $1937^{2}$, Salinas recurre a la imagen de la hiedra frondosa para describir la profusión de cartas, respuestas, pareceres, censuras, apologías, ilustraciones y comentarios, provocada por la aparición de los grandes poemas de Luis de Góngora. Como bien es sabido, hay que inscribir estas palabras de Salinas en el

\footnotetext{
${ }^{1}$ Nuestro más sincero agradecimiento a Mercedes Blanco, Jaime Galbarro García, François-Xavier Guerry, Guillaume Lancereau y Aude Plagnard, atentos lectores que han mejorado este artículo con sus correcciones y consejos.

${ }^{2}$ En las Turnbull Foundation Poetry Lectures de 1937, publicadas en inglés en 1940 y en versión española en 1976 (Salinas, 2007: 405-497).
} 
redescubrimiento de Góngora impulsado por la generación del 27 a la que él mismo pertenece. Sin embargo, también constituyen un testimonio del interés inédito que despierta de manera coetánea el complejo proceso de recepción de las obras del poeta cordobés tras su difusión y durante todo el siglo XVII. De hecho, en cincuenta años de producción crítica alrededor del estilo de Góngora, entre 1613 y $1662^{3}$, se elabora una reflexión profunda en torno a la nueva poesía del cordobés. Esta reflexión tomó la forma de una verdadera guerra emprendida por eruditos y escritores de la altura de Pedro de Valencia, Francisco Fernández de Córdoba, Juan de Jáuregui, Francisco Cascales, Félix Lope de Vega Carpio, Francisco de Quevedo o García de Salcedo Coronel, además del mismo Góngora. Como sugiere Salinas con ironía, estamos ante el debate más importante de la historia moderna de la crítica española.

Tras casi un siglo de estudios gongorinos, que arranca con Dámaso Alonso, Raymond Foulché-Delbosc y Alfonso Reyes, el interés por la polémica que rodea la obra de don Luis culmina con la catalogación establecida por Robert Jammes (1994: 607-719) y publicada en apéndice de su edición de las Soledades. El catálogo de Jammes, recensión exhaustiva de un legado crítico anteriormente disperso, ha sido estímulo y referente para una nueva generación de estudios, en la que destacan los trabajos de eminentes gongoristas como Mercedes Blanco, Antonio Carreira, Begoña López Bueno o Joaquín Roses Lozano 4 .

Siguiendo este impulso nace en 2013 el proyecto Góngora del Labex OBVIL, concebido y dirigido por Mercedes Blanco, cuyo primer objetivo consiste en editar en formato XML el conjunto de textos de la polémica gongorina en una plataforma abierta en $\mathrm{HTML}^{5}$. El proyecto de edición pretende reunir dos metodologías y dos aspiraciones tan distintas como complementarias: la edición crítica y anotada por una parte y la edición digital enriquecida con metadatos y contenido multimedia por otra. El resultado al que aspira el proyecto es el de poner a disposición del lector, en formato XML, TXT, EPUB y HTML, en abierto, un amplio conjunto de textos del siglo XVII relacionados en mayor o menor medida con la recepción de la obra de Luis de Góngora. Además, las piezas de la polémica, íntimamente conectadas entre sí, componen un conjunto intertextual idóneo para la explotación y el desarrollo de las posibilidades prometedoras de una edición digital (Allés Torrent, 2015: 18-21), empezando por el hipervínculo.

\footnotetext{
${ }^{3}$ En el año 1662 Espinosa Medrano publica en Lima su Apologético, considerado con razón el último documento importante de la polémica gongorina (Jammes, 1994: 607-719; Blanco, 2010: 169-207). Para una cronología de la polémica gongorina y de sus actores, accesible desde Jammes (1994: 607-719), Roses Lozano (1994: 9-65) y Blanco (2012: 63-68).

${ }^{4}$ Sus investigaciones reúnen de manera sistemática el estudio de la figura y obra de Góngora y el análisis de su controvertida recepción coetánea. Remitimos a los trabajos más recientes de cada uno: Blanco (2012: 49-70; 2013: 7-40), Carreira (1998), López Bueno (2013a: 123-142; 2013b: 724-748), Roses Lozano (1994: 133-183; 2004).

${ }^{5}$ En el sitio web del OBVIL (http://obvil.paris-sorbonne.fr/corpus/gongora/) ya se pueden consultar las ediciones de algunas piezas maestras de la polémica. La primera y la última de la polémica. También El Parecer de Fernández de Córdoba, a cargo de Muriel Elvira (2015), y el Apologético de Espinosa Medrano, a cargo de Héctor Ruiz (2017).
} 
El corpus que editamos contiene un centenar de piezas de naturaleza muy heterogénea que abarcan y amplían el catálogo de Jammes y que, sin contar los testimonios de difícil datación, van de 1613 a 1685. Como han destacado los especialistas, en particular Roses Lozano (1994: 9-65) y Blanco (2012: 49-70), la discusión sobre la legitimidad del estilo gongorino, sobre la oscuridad o la dificultad de su sintaxis y sobre la conveniencia o no de su imitación, temas centrales de la polémica, se encuentra en un número considerable de comentarios, apologéticos y censuras, textos todos explícitamente polémicos. Pensamos, por ejemplo, en el Parecer de don Francisco de Córdoba acerca de las Soledades, a instancia de su autor (1614) o en el Discurso poético de don Juan de Jáuregui (1624), ambos editados en el marco del proyecto (Elvira, 2015; Blanco, 2016). Sin embargo, los mismos temas, o parte de ellos, se encuentran también en otros textos, sólo tangencialmente polémicos. Por ejemplo, en la novela El culto graduado de Alonso de Castillo Solórzano, de 1625 (Castillo Solórzano, 2015), o en el León prodigioso de Gómez de Tejada (Periñán, 1976: 153-186), un cuento alegórico de similares características ${ }^{6}$. Textos plena o tangencialmente polémicos comparten, pues, el mismo bagaje conceptual y una serie de problemáticas afines. Por tanto, algunos han de ser considerados como literatura secundaria, de crítica y comentario, mientras que otros ilustran cómo irradió la controversia en torno a Góngora y a su imitación, en obras y géneros tan distintos como la novela, el sermón o el teatro ${ }^{7}$.

Ahora bien, además de la coincidencia temática o conceptual, también un rasgo formal destaca como ingrediente característico de la polémica en su conjunto y, a la vez, como criterio principal para la constitución del corpus que editamos. Se trata de la intertextualidad. Como no podía ser de otro modo, el pilar fundamental de la polémica es el mismo Góngora y su estilo poético, reconocible a lo largo de los textos críticos aun cuando no se nombre al poeta cordobés. Sin embargo, si bien el horizonte intertextual de cada texto polémico abarca, por un lado, a Luis de Góngora, por el otro está abierto al resto de testimonios de la polémica, ya estén a favor o en contra del vate, ya sean manuscritos o impresos, mencionados a partir de un escrito o en base a relaciones orales, o incluso a rumores. Tal parece efectivamente ser el caso cuando, en su Apologético en favor de don Luis de Góngora (1662), Espinosa Medrano menciona a Pedro de Oña como detractor del poeta, aun cuando la crítica lo reconoce como un imitador de Góngora en América (Sánchez Robayna, 2012: 189):

El docto chileno y artificiosísimo poeta indiano, el licenciado Pedro de Oña, con ser de los que sintieron y aun escribieron mal de este dulcísimo cisne (ignoro el motivo) nunca le reprobó los hipérbatos (González Boixo, 1997: fol. 16r).

\footnotetext{
${ }_{7}^{6}$ El proyecto Góngora del Labex OBVIL prepara una nueva edición del León prodigioso.

${ }^{7}$ En El castigo sin venganza, I, v. 5-35, aparece una breve sátira de los poetas destos de la nueva seta/ que se imaginan divinos (v. 19-20), en los que hay que reconocer a la secta de los imitadores de Góngora (Carreño, 2010: 119-123).
} 
Esta práctica de la alusión, ingrediente característico de la argumentación en la polémica, se encontraba ya, años antes, en los largos comentarios de la obra gongorina. Véase, por ejemplo, este fragmento de las Lecciones solemnes de José de Pellicer, donde el controvertido erudito ${ }^{8}$ menciona a Gabriel de Roa, personaje ausente de los principales estudios de la polémica, entre los hermeneutas de unos versos especialmente difíciles de la Soledad Primera (vv. 566-570) ${ }^{9}$ :

N[uestro] amigo Gabriel de Roa, gran poeta, gran amigo de don Luis y grande imitador suyo, de cuyo manuscrito me he valido, me advirtió que lo que don Luis quiso decir allí era que cada zagala limpiaba a su esposo con puñados de rosas deshojadas el sudor de su frente (Pellicer, 1630, col. 482).

En definitiva, cada testimonio de la polémica supone un posicionamiento de su autor con respecto a la poesía gongorina y al resto de la polémica, o, por lo menos, al aspecto que de ella conoce e interesa al polemista. Contemplada de forma individual, cada pieza del debate se presenta como una vitrina de los demás testimonios, sean ya conocidos o todavía ignorados, conservados o no. De esta manera, la polémica se define por su carácter marcadamente intertextual, perfilándose como un corpus abierto compuesto por la superposición del horizonte intertextual de los testimonios que la componen.

Ahora bien, el concepto de intertextualidad, y el importante impulso que el estructuralismo le dio a su estudio y al de la transtextualidad en sus múltiples facetas, desemboca en la definición del llamado hipertexto o architexto, referido a un escrito elaborado a partir de otro, como la polémica a partir de la obra de Góngora. El concepto de hipertexto, paralelamente, ha sido retomado por las Humanidades Digitales en base a premisas distintas y complementarias. En efecto, el hipertexto informático es ante todo un texto electrónico y navegable. Desarrollado con el aporte instrumental del hipervínculo, este presenta tres características materiales que lo distinguen del texto en formato papel: la implementación de zonas manipulables correspondientes, por ejemplo, a los hipervínculos; la posibilidad del movimiento a partir de estos hipervínculos; y la variabilidad o labilidad permitida por la actualización informática de las ediciones con el paso del tiempo (Saemmer, 2015: 639). Ambos conceptos del hipertexto, el del estructuralismo y el de las Humanidades Digitales, se superponen o pueden hacerlo en casos concretos como el de la polémica gongorina. Para ilustrarlo, tomamos el ejemplo siguiente de Salazar Mardones, que en su extenso comentario

\footnotetext{
${ }^{8}$ Recordemos que el juicio negativo de Dámaso Alonso, objeto de un célebre artículo titulado Todos contra Pellicer, publicado por vez primera en 1955 (Alonso, 1982: 462-487), pesó durante muchos años sobre la obra y la personalidad del autor de las Lecciones solemnes. A día de hoy, gracias también a un retorno a los comentarios de Góngora generalizado en la crítica, el proceso de rehabilitación del erudito puede darse por acabado y, por tanto, resulta ya bastante injusto mantener los prejuicios del maestro (Ponce Cárdenas, 2014: 50).

${ }^{9}$ Al citar la obra de Góngora remitimos siempre a la edición de Antonio Carreira (2016), sobre la que nos detendremos más adelante en ese artículo.
} 
de la Fábula de Píramo y Tisbe de Luis de Góngora, concluía así un razonamiento sobre el estilo oscuro y difícil de la fábula gongorina:

Otros muchos lugares han calumniado en las obras de don Luis, unos por no entenderlas, $y$ otros con ánimo de ofenderle, pero a todas satisfacen con mucha erudición sus doctos. Los comentadores don García de Salcedo Coronel, don Joseph Pellicer de Tobar, y también don Martín de Angulo y Pulgar en sus eruditas Epístolas satisfactorias. Véanse todos tres, que en ellos se hallará copiosamente cuanto es necesario, así para la verdad del sentido, como para el lustre y ornato de ella (Salazar Mardones, 1636: f. 77r.).

El reenvío explícito tanto a lugares de la obra de Góngora como a algunos de sus valedores es propio de un hipertexto intertextual. De hecho, tales alusiones, para ser plenamente apreciadas por el lector, exigen un dispositivo como el del hipertexto electrónico, manipulable y navegable. La apertura del corpus, ya mencionada y aquí visible en las vagas alusiones a los anti-gongorinos, obliga a considerar la investigación como una tarea a largo plazo, compatible con la labilidad del hipertexto como texto digital (Saemmer, 2015: 639) ${ }^{10}$.

Así pues, el dispositivo del hipervínculo y la noción del hipertexto, dentro del aparato conceptual y de los instrumentos propios de las Humanidades Digitales, se perfilan como un aporte editorial y teórico idóneo para un corpus tan interconectado como el de la polémica gongorina. A su vez, el estudio del debate en torno a Góngora constituye un laboratorio ideal para la reflexión del humanista digital sobre unos instrumentos de investigación en constante desarrollo. Una edición digital del corpus de la polémica gongorina reclama la construcción de un hipertexto (digital) del hipertexto (intertextual). Pero no cabe duda de que, como señala Alexandra Saemmer, el concepto del hipertexto digital y el dispositivo del hipervínculo plantean problemas fecundos también para el estudioso de la literatura:

Los enfoques críticos deben evolucionar y perfilarse para tomar en consideración las especificidades del texto digital: el hipervínculo como texto que debe ser leído en función de figuras de una retórica y de una poética de la (de)coherencia; el hipervínculo como texto que debe ser manipulado, con el clic o con otros gestos de carácter potencialmente icónico que deben ser analizados en relación con los signos alfabéticos; la animación textual, que apela a otra forma de iconicidad basada en el movimiento; la relación texto-imagen, en la página-pantalla o entre las páginaspantalla; la relación texto-sonido; la naturaleza codificada del texto numérico y su influencia potencial sobre la semiosis; y por último la inexorable labilidad del texto digital, el hecho de que sus formas no sean nunca estables (Saemmer, 2015: 648) ${ }^{11}$.

\footnotetext{
${ }^{10}$ Alexandra Saemmer habla, en francés, de texte numérique. Sobre el hipertexto intertextual (estructuralista) y el electrónico, propio de las Humanidades Digitales, se pueden consultar las fuentes siguientes. Un resumen de la historia de los conceptos de architexto e hipertexto se encuentra en Genette (1982: 7-14). Para un repaso de la aparición del hipertexto de las humanidades digitales, véase Radiant Textuality de Jerome McGann (2001: 3-5). Una discusión sobre la relación entre el estructuralismo y las Humanidades Digitales se encuentra en Rojas Castro (2015: 15-16); un buen balance sobre el hipertexto digital en Saemmer (2015: 637-652).

${ }^{11}$ En el texto original, "Les approches critiques doivent évoluer et s'affiner pour prendre en compte les spécificités du texte numérique: I'hyperlien en tant que texte à lire mobilisant les figures d'une rhétorique et d'une poétique de
} 
Dejando de lado la relación entre texto y sonido, y centrándonos por tanto en la relación texto a texto y texto-imagen, a continuación, estudiaremos el dispositivo del hipervínculo aplicado a la polémica gongorina y la construcción a partir de tal instrumento de una serie de hipertextos, que desemboca en una red o tabla de materias dinámica de la polémica. Un hipertexto de componente ante todo visual, que, dotando al lector moderno de nuevos gestos teóricos y prácticos, pretende llevarlo hacia nuevas lecturas de este corpus tan importante y peculiar de textos áureos.

\section{LA EDICIÓN DIGITAL DE LA OBRA DE GÓNGORA Y LA POLÉMICA GONGORINA}

Entre 2013 y 2016, la tarea realizada por el proyecto va encaminada a reunir y editar en una única plataforma HTML, por un lado, los textos de la polémica gongorina cuidadosamente anotados y acompañados de estudios introductorios; por otro, la obra completa de Luis de Góngora, editada por Antonio Carreira (2000), a partir de una revisión y ampliación de su ya canónica edición de la Fundación José Antonio de Castro. En ambos casos, estas ediciones digitales tratan de "conjugar la práctica de la crítica textual tradicional con las posibilidades del soporte digital" (Allés Torrent, 2015: 18), aunando la anotación filológica con el enriquecimiento en lenguaje XML a partir de la versión P5 de la Text Encoding Initiative (TEI). El resultado, todavía en desarrollo, es un hipertexto de la polémica en el que, a partir de la anotación filológica y de una codificación ad hoc mediante metadatos, una serie de hipervínculos conectan los poemas de Góngora con los textos polémicos y, a su vez, a los textos polémicos entre sí.

\subsection{De la digitalización a la edición digital y de la recensión a la reunión del} corpus

El investigador que estudie el corpus de la polémica gongorina, aún hoy, comprobará que sus testimonios siguen siendo difíciles de encontrar. Efectivamente, sólo una quinta parte conoció la imprenta (Jammes, 1994: 607-719), mientras que la mayoría se ha transmitido de forma manuscrita y se encuentra en bibliotecas y archivos dispersos por Europa y América. Bien es verdad que algunos impresos que componen el corpus pueden ser consultados a

la (dé-)cohérence; l'hyperlien en tant que texte à manipuler, par clic ou d'autres gestes dont le caractère potentiellement iconique doit être analysé en relation avec les signes alphabétiques; l'animation textuelle mobilisant une autre forme d'iconicité fondée sur le mouvement; la relation texte-image, sur la page-écran et entre les pagesécran; la relation texte-son; la nature codée du texte numérique et son influence potentielle sur la sémiose; et enfin la labilité inexorable du texte numérique, le fait que ses formes ne sont jamais stables" (traducción propia). 
partir de repositorios digitales ${ }^{12}$, como los principales comentarios de la obra de Góngora (Pellicer, 1630; Salazar Mardones, 1636; Salcedo Coronel, 1644). Sin embargo, como en otros casos referentes a la literatura de la Edad Moderna, asistimos con estas digitalizaciones, en palabras de Damian-Grint (2007: 110), a una total primacía de la imagen ${ }^{13}$. Las obras disponibles en estos repositorios son en efecto mayoritariamente imágenes puras, en algunos casos enriquecidas para configurar un libro navegable.

Cuando hay un reconocimiento textual mediante OCR, los archivos de texto obtenidos a partir de estas imágenes añaden a los consabidos errores de lectura de los programas de reconocimiento textual el reto de enfrentarse a varias lenguas en el mismo texto y hasta en la misma página. Las citas eruditas abundan sobre todo en géneros como el comentario, como puede observarse en la llustración y defensa de la Fábula de Píramo y Tisbe de Cristóbal de Salazar Mardones (1636). En los folios 23r y $23 \mathrm{v}$ se leen citas de Ovidio, Bernardo Tasso, Garcilaso, Camoes y Teócrito: en italiano, español, portugués y latín. La reproducción digital no subsana esta carencia en lo que se refiere a la disponibilidad para el investigador de los textos del corpus polémico, por lo que es necesario redoblar los esfuerzos de edición que han marcado los estudios gongorinos de los últimos años. En efecto, superada la etapa inicial de la recensión, la investigación de la polémica ha discurrido decididamente por la senda de la edición filológica o, en algunos casos, facsímil ${ }^{14}$. De las veinticinco ediciones modernas de documentos de la polémica catalogadas por Mercedes Blanco (2012: 65-68), quince corresponden al período 1925-1992, una media de una cada cuatro años y medio; y diez al período 1998-2009, una media de casi una al año. El trabajo editorial del proyecto Góngora se inscribe por tanto en una tradición filológica y ecdótica especialmente activa en los últimos tiempos, enriquecida, sin embargo, en el marco del proyecto con la recolección exhaustiva de todas las piezas conocidas y conservadas de la polémica, y su reunión y puesta en línea en una única plataforma virtual.

\subsection{Un modelo práctico de complementariedad de la anotación filológica y del} enriquecimiento por metadatos: la cadena de producción del proyecto Góngora

En su artículo ya mencionado sobre las ediciones digitales, Susana Allés Torrent (2015: 18) reclama con razón modelos teóricos para el formato digital de las ediciones

\footnotetext{
${ }^{12}$ La Biblioteca Digital Hispánica contiene digitalizaciones de Pellicer (1630), Salazar Mardones (1636) y Salcedo Coronel (1644). También se encuentran estos comentarios en HathiTrust, Google Books o la Biblioteca Virtual del Patrimonio Bibliográfico, como se indica en la bibliografía.

${ }^{13}$ En inglés, el autor habla de the primacy of the image.

${ }^{14}$ Reproducción de una edición impresa, como las Lecciones Solemnes de Pellicer (1971), a partir de la edición de Madrid de 1630. En este caso se reordena la disposición de la portada y la portadilla y se eliminan marcas y anotaciones de lectura. Accesible desde también la edición facsimilar del Apologético en favor de don Luis de Góngora de Juan de Espinosa Medrano (González Boixo, 1997: 125-244).
} 
científicas, puesto que para el formato papel "existen metodologías claras y presentaciones concretas". No aspiramos aquí a responder a esta demanda metodológica. Sin embargo, guiados por el convencimiento de que la edición digital es el resultado de una mutación o metamorfosis del libro (Jahjah, 2015: 693-694; Souchier, 2013: 35-37), consideramos la complementariedad entre la edición papel y la edición digital como un requisito fundamental de nuestras ediciones. Esto nos lleva a exponer un modelo práctico de complementariedad entre el lenguaje informático de la TEI y la tradición filológica de la edición académica, entre las metodologías claras y presentaciones concretas de las ediciones científicas en papel y el aparato instrumental y los dispositivos de lectura del formato digital. Exponiendo la génesis de (nuestro) proyecto, a caballo entre la Filología tradicional y las Humanidades Digitales, pretendemos colaborar a la institucionalización (Berra, 2015: 620) de una metodología digital de la Filología.

En lo que se refiere a la presentación, las ediciones del proyecto Góngora difieren poco en apariencia del formato papel. Cada texto viene precedido por una introducción estructurada de forma homogénea para todas las ediciones y cada texto cuenta con una detallada anotación filológica y un aparato de variantes. De esta manera, cada edición cuenta con tres niveles de anotación: una anotación del aparato crítico, una anotación filológica y, en los casos en los que sea necesaria, una anotación que documente los apuntes marginales de los textos editados. Las dos primeras categorías aparecen en HTML al final del documento y en EPUB a pie de página, mientras que la disposición de las notas marginales trata de respetar de manera mimética la morfología de la página en el original. De esta manera, la anotación del editor y el estudio introductorio prolongan la tradición filológica en papel en la que se insertan las ediciones recientes y autorizadas de los textos de la polémica gongorina. Además, al respetar la separación entre el margen y el cuerpo de texto, la disposición de las notas de autor en la página imita el formato papel original. Ahora bien, esta voluntad clara de respetar la morfología de la página, manuscrita o impresa, que corresponde al skeuomorfismo que los especialistas del libro identifican en los nuevos dispositivos de lectura digital (Jahjah, 2015: 699), podía peligrar en HTML por la lectura en cascada. No obstante, tal skeuomorfismo cuenta en el proyecto con el apoyo de un contenido multimedia añadido a la edición: las imágenes de la reproducción digital de cada testimonio impreso o manuscrito. Son imágenes puras, adheridas a la secuencia textual mediante un anclaje XML a partir de los saltos de página o de folio correspondientes al texto editado.

En lo que se refiere a la metodología, el código fuente empleado para las ediciones digitales es el lenguaje XML de la TEl en su versión P5. Este lenguaje goza de un claro reconocimiento científico en el área de las Humanidades Digitales, atestiguado entre otros por James Cummings (2007: 457-464) o por Susana Allés Torrent (2015: 18-20). Sin embargo, para alcanzar la complementariedad entre las metodologías propias del formato papel y el 
lenguaje $\mathrm{XML}$ de las ediciones digitales, una serie de consignas editoriales y de instrumentos informáticos son imprescindibles. Como no todos los editores del proyecto conocen el lenguaje XML, el transformador Odette (Glorieux, 2015) permite convertir documentos de texto de extensión .odt en archivos XML a partir de una selección operada por Vincent Jolivet y Frédéric Glorieux (2015) en el estándar P5 de la TEI ${ }^{15}$. Con este transformador, la anotación y el enriquecimiento van de la mano. En efecto, empleando una plantilla en .odt, cada editor puede anotar su texto y preparar su posterior enriquecimiento con metadatos, que será efectivo en formato XML. La plantilla permite marcar con estilos predeterminados en el procesador de textos las autoridades aducidas por los polemistas, las citas, los títulos de obras y las menciones de otros autores pertenecientes al corpus polémico. Los estilos predeterminados, reconocidos por Odette, son volcados en forma de etiquetado al XML. De esta manera, la primera etapa del enriquecimiento del texto es obra del editor, independientemente de su conocimiento del lenguaje XML.

Una segunda etapa corresponde al enriquecimiento en XML de las ediciones. El transformador Odette conserva el trabajo digital de los editores en formato XML, mientras que un equipo compuesto por varios miembros del proyecto ${ }^{16}$ enriquece el texto a partir de la anotación filológica, siguiendo un protocolo estricto para completar el marcado de las autoridades, las citas, los polemistas y los títulos de obras con otros metadatos. Para ello, todos los editores del proyecto comparten las mismas normas editoriales. Así, por ejemplo, en nota a pie de página se marca mediante un sencillo código la localización de un verso de Góngora en la edición de las obras completas revisadas para el proyecto por Antonio Carreira: este código inscrito en el documento .odt y conservado por Odette es fácilmente codificado en XML en esta segunda etapa.

Esta cadena de producción trata, por tanto, de aunar el trabajo editorial tradicional y el enriquecimiento con metadatos. En una primera etapa, el editor filológico es al mismo tiempo editor digital, puesto que marca con estilos predeterminados en el procesador de textos una serie de informaciones presentes en el texto que está editando. En una segunda etapa, a partir de la anotación filológica de cada editor, un segundo enriquecimiento se basa en abreviaturas consensuadas para marcar informaciones añadidas por el editor. De esta manera, hay una continuidad entre el trabajo filológico y el trabajo digital durante todo el proceso de edición y codificación de los textos.

\footnotetext{
${ }^{15}$ El esquema de XML en el que se basa Odette es el Teibook del OBVIL desarrollado por Vincent Jolivet y Frédéric Glorieux (2015). En este aspecto, Odette supone una simplificación del OxGarageConversion desarrollado en la Universidad de Oxford para TEI (http://www.tei-c.org/oxgarage/).

${ }^{16}$ Hasta la fecha, han colaborado Jaime Galbarro García, François-Xavier Guerry, Felipe Joannon, Aude Plagnard y los autores de estas líneas, Sara Pezzini y Héctor Ruiz.
} 


\subsection{Editar a Góngora en su polémica: del hipervínculo al hipertexto}

El proyecto publica, como ya hemos anticipado, las Obras completas de don Luis de Góngora gracias a la colaboración de Antonio Carreira. La reciente puesta en línea de la Poesía (Carreira, 2016), a la cual se añadirá pronto la sección relativa al teatro, representa, stricto sensu, la edición más autorizada de la obra del cordobés. Se trata por tanto de la última versión, revisada, puesta al día y dotada de un nuevo estudio introductorio, de la que el eminente especialista publicó en las ediciones de la Fundación José Antonio de Castro (Carreira, 2000). Como todas las publicaciones del proyecto, se encuentra en línea de forma gratuita y bajo una licencia Creative Commons (BY NC ND).

Dicho esto, la edición digital de las Obras completas de Luis de Góngora no constituye una simple revisión de la publicada por la Fundación José Antonio de Castro. La inscripción en lenguaje XML de una serie de metadatos en la poesía del cordobés transforma esta publicación (Carreira, 2016), en la primera edición digital de la obra íntegra del poeta ${ }^{17}$. De hecho, la necesaria codificación en lenguaje TEI a la que hemos sometido a la Poesía, ha permitido añadir una serie de datos semánticos y formales que, obviamente, la edición en papel no podía contemplar. Este proceso de enriquecimiento se apoya en el estándar P5 de la TEl aplicado a la poesía: cada estrofa ha sido codificada con la etiqueta $<$ lg $>$ y cada verso con la etiqueta $<1>$, así como las acotaciones, títulos o notas con sus etiquetas correspondientes. Remitimos al documento en marcado TEI disponible en el repositorio digital del proyecto $^{18}$. Además de esta estructuración semántica del documento, cada verso del poema consta de un atributo numérico (@n) y de una identificación en XML (@xml:id) a partir de la cual se construyen los hipervínculos; el primer verso de cada poema es indexado para la creación de un índice de primeros versos. Los versos ajenos a Góngora constan del atributo @xml:id pero no del atributo @n puesto que no entran en la numeración del poema gongorino: tal es el caso del poema 343, que glosa una "redondilla ajena"19. Se han marcado también los estribillos de romances y canciones con el atributo @rend=“refrain" y las cesuras, como en el poema 340 , con la etiqueta correspondiente (<caesura/>): ambos metadatos compaginan la

\footnotetext{
${ }^{17}$ Recordamos que en fecha reciente y de manera independiente al OBVIL, Antonio Rojas Castro ha editado en XML las Soledades de Góngora. Esta edición crítica, con su aparato de variantes, ha sido objeto de la tesis doctoral de Rojas y puede consultarse en línea: Editar las "Soledades" de Luis de Góngora en la era digital. Texto crítico y propuesta de codificación XML/TEI (dirigida por José María Micó y defendida en la universidad Pompeu Fabra de Barcelona el 22 de noviembre de 2015). El texto en http://www.tdx.cat/handle/10803/323083.

${ }^{18}$ Se encuentra en la página: http://obvil.paris-sorbonne.fr/corpus/gongoral. Corresponde en concreto al enlace http://obvil.paris-sorbonne.fr/corpus/gongora/gongora obra-poetica/.

${ }^{19}$ En el que la codificación de la redondilla ajena se ha resuelto de la siguiente manera:

$"<\lg >$

$<\mid \mathrm{xml}:$ id="|343.1a" $>$ ¿Para qué me dais tormento, $</ \mid>$

$<$ xml:id=“|343.2a" >aprovechando tan poco?</l>

$<$ xml:id="|343.3a" $>$ Perdido, mas no tan loco $</ \mid>$

$<$ xml:id="|343.4a" >que descubra lo que siento. $</ \mid>$

$</ l g>"$.
} 
información semántica y de maquetación. Por último, los versos mútilos en los poemas dialogados han sido codificados según el estándar TEI con el atributo @part, marcando los distintos momentos métricos del verso como en ejemplo siguiente:

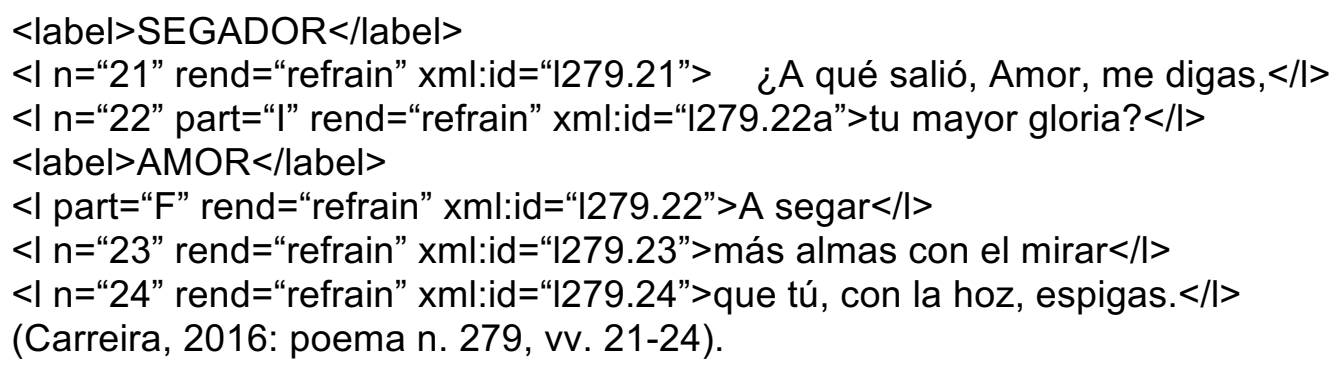

En resumidas cuentas, en el caso de la edición de Góngora del OBVIL, la imitación de la edición canónica en papel (Carreira, 2000) y la inscripción de metadatos, ha llevado a una codificación que supera la simple presentación. Así, los metadatos aplicados al corpus poético enriquecen la mirada crítica de los especialistas del vate cordobés y cumplen una ambición práctica y teórica, que, en los albores del proyecto, su promotora había formulado de la manera siguiente:

\begin{abstract}
Para dotar la polémica gongorina del pleno valor histórico, teórico y crítico que virtualmente posee, se echa de menos una herramienta que permita coordinar las investigaciones de modo que sus resultados se potencien mutuamente [...] esos fenómenos laten y actúan en los textos, y permiten o permitirán replantear la descripción y explicación de los hechos literarios a cualquier escala, desde el dato textual más menudo hasta épocas enteras o categorías tan generales como la narración, el verso o el estilo (Blanco, 2013: 9).
\end{abstract}

De hecho, la edición digital de la Poesía publicada en el OBVIL (Carreira, 2016) no sólo permite navegar en el corpus gongorino de manera simple e inmediata, pues cuenta con un buscador, sino también moverse del texto a su hipotexto a través del instrumento del hipervínculo. Gracias a esta herramienta, por primera vez, el corpus crítico de la polémica se sitúa dentro del objeto mismo del debate. En concreto, en la edición de la Poesía del OBVIL (Carreira, 2016), todas las veces que un polemista se refiere a un verso, a una palabra, a una construcción sintáctica o a una figura de un determinado poema de Góngora, esta referencia se visualizará en la propia edición del poema en forma de hipervínculo. Este hipervínculo es recíproco: de Góngora a la polémica y de la polémica a Góngora. El etiquetado conecta por tanto el locus poético y su correspondiente locus crítico. A partir del modelo de la anotación marginal, presente en numerosos textos de la polémica para dar una referencia bibliográfica, 
el hipervínculo aparece en el margen del poema gongorino en que está inscrito ${ }^{20}$. El resultado de esa operación, ya parcialmente apreciable en el caso de los versos de íncipit de la Primera Soledad ${ }^{21}$ se completará a medida que se publiquen los textos de la polémica hasta llegar a una visualización exhaustiva de lugares que interesan a los detractores o defensores de la poesía del cordobés. En definitiva, el hipervínculo funciona como una lupa posicionada de manera coincidente sobre la poesía y sus comentarios, que permite sobrevolar el texto gongorino, para observarlo a partir de su recepción coetánea, o para hacer lo propio, a la inversa, con la polémica gongorina.

La lectura distante ${ }^{22}$ de Góngora tiene, en la edición de OBVIL, varios soportes: el hipervínculo ya mencionado, un motor de búsqueda que puede abarcar tanto la poesía de Góngora como su polémica y, por último, una tabla de materias múltiple, ya que el texto de Góngora puede ser consultado a través de un índice que recoge los poemas, numerados consecutivamente y ordenados por fecha de composición, título y primer verso, en función de lo que el lector elija. Un segundo índice, actualmente en desarrollo, permite navegar en el texto gongorino a través de una nube de palabras construida con un software libre llamado IRaMuTeQ a partir de los sustantivos y adjetivos más frecuentes en su obra (Baril y Garnier, 2015). En ambos casos, como corresponde a una tabla de materias en HTML, el índice consta de hipervínculos que reenvían al lector, con un simple clic, al lugar elegido. La nube de palabras y la tabla de materias dinámica forman dos índices distintos y complementarios, donde el hipervínculo juega siempre un rol a la vez práctico y semántico de importancia capital.

En lo que se refiere a la nube de palabras, esta constituye no sólo un índice mimético y multimedia de la edición, sino que invita también a un análisis estilístico de la poesía gongorina. Efectivamente, permite visualizar cuáles son los sustantivos y adjetivos más frecuentes en el corpus gongorino. Construida a partir de un algoritmo que desarrolla las frecuencias léxicas en función de las categorías gramaticales y las organiza en una tabla estadística (aspectos sobre los cuales no nos podemos detener en estas páginas), la nube invita al humanista digital a construir ontologías (Rastier, 2004: 37-38) de la poesía gongorina o, dicho de otro modo, un diccionario contextual del léxico gongorino. Con ese mismo propósito, el hipervínculo permite reenviar al lector inmediatamente, a partir de la nube, al contexto de la palabra representada en todos los lugares del texto gongorino, abriendo así

\footnotetext{
${ }^{20}$ El hipervínculo toma por tanto la forma de una nota: "<note place="margin" $><$ ref target="http://obvil.parissorbonne.fr/corpus/gongora/1614 parecer/body-1\#ref1" $>$ Parecer de don Francisco de Córdoba acerca de las $<$ hi rend="i">Soledades</hi> a instancia de su autor, Francisco de Córdoba, 1614</ref $></$ note $></ \mid>$ ".

${ }^{21}$ Como el lector podrá apreciar en: http://obvil.paris-sorbonne.fr/corpus/gongora/gongora obrapoetica/poem264B.

${ }^{22}$ Aludimos aquí a la célebre expresión de Franco Moretti que titula su no menos célebre ensayo fundacional sobre la aplicación de recursos digitales e informáticos al campo de los estudios literarios (Moretti, 2005). En su investigación, el catedrático de Stanford propone estudiar la literatura a partir de objetos artificiales obtenidos con metodologías cuantitativas y digitales (gráficos, mapas, tablas, etc.). La lectura distante de Góngora, a su vez, supone leerlo a partir de los hipervínculos y del hipertexto digital de la polémica.
} 
una reflexión sobre el abanico temático del universo poético del autor de las Soledades desvelado ahora de manera automática (Ganascia, 2015: 628) y sintética ${ }^{23}$. Enfocada de esta manera, por lo tanto, la edición digital de Góngora funciona, en palabras de Marc Jahjah, como un "Proteo dotado del poder de transformarse en el momento en el que uno se aproxima a él" (2015: 699). Lo mismo ocurre con la polémica gongorina en su conjunto, gracias a la construcción de tablas de materias hipertextuales, estructuradas a partir de hipervínculos cruzados entre los versos de Góngora y su controversia exegética.

\section{ANÁLISIS DE REDES E HIPERTEXTO: HACIA UNA TABLA DE MATERIAS DINÁMICA DE LA POLÉMICA GONGORINA}

Entre los métodos cuantitativos de las Ciencias Humanas y Sociales, el análisis de redes, que se desarrolla a partir de 1970 en los campos de la Psicología, la Sociología, la Historia y la Demografía (Lemercier y Zalc, 2008: 80), ha vivido un desarrollo específico en el campo de las Humanidades Digitales con programas de análisis y visualización como Pajek (Laurent y Mercklé, 2011) o Gephi (Heymann, 2014: 612-625), entre otros (Wasserman y Faust, 1994: 735-737). Estos programas, a partir de la metodología del social network analysis, permiten estudiar y representar mediante gráficos un número importante de "datos relacionales o network data: datos sobre las relaciones que unen o no a un conjunto de individuos estadísticos" (Lemercier y Zalc, 2008: 84). Las aplicaciones de esta metodología, aun antes del desarrollo de los programas mencionados, han dado sus frutos en numerosas áreas de las ciencias sociales (Wasserman y Faust, 1994: 3-22), puesto que los individuos estadísticos considerados pueden ser personas, municipios $u$ organizaciones, pero también bibliotecas, textos o relaciones de coocurrencia lingüística (Lemercier y Zalc, 2008: 84-89; Wasserman y Faust, 1994: 28-66). Aplicado al estudio de un corpus intertextual como el de la polémica gongorina, este método ha dado excelentes resultados en estudios pioneros como el que Douglas R. White y H. Gilman McCann dedicaron al nacimiento de la química moderna. A partir del análisis de las citas en un corpus de publicaciones científicas inglesas y francesas entre 1760 y 1795, documentaron gracias al análisis de redes el cambio de paradigma propio de una verdadera revolución científica (White y McCann, 1988: 387-390).

Proponer un estudio de la polémica gongorina a partir de esta metodología para así documentar una revolución estética es una tarea que se nos antoja necesaria, pero que no tiene cabida en estas líneas. Nos gustaría, sin embargo, proponer una aplicación de los programas de análisis y visualización de redes para construir un índice dinámico de la

\footnotetext{
${ }^{23}$ Además, el análisis del gráfico va de la mano del estudio de la tabla estadística producida por el mismo software, que ofrece, entre otros datos, las frecuencias clasificadas en función de las categorías gramaticales. Esta tabla estadística remite asimismo a la sección del corpus gongorino en que se encuentra cada palabra.
} 
polémica gongorina que permita nuevas lecturas de la misma. Exponemos a continuación, pues, las bases metodológicas de un trabajo todavía en desarrollo.

En el proyecto Góngora, como ya ha sido descrito, el enriquecimiento de los textos con metadatos XML atendía en una primera etapa a las citas, las referencias a otros autores (polemistas, autoridades) y a los títulos de obras. En una segunda etapa, las citas de Góngora han sido objeto de un marcado específico acompañado por la construcción de hipervínculos cruzados: de la polémica a Góngora y de Góngora a la polémica. Todos los datos marcados son por tanto datos relacionales propios de un corpus intertextual. Los primeros abren el corpus al espectro completo de las referencias eruditas de cada texto, mientras que los segundos constituyen una red cerrada, que conecta el corpus de la polémica con las Obras completas de Luis de Góngora (Carreira, 2000). Una vez completado el segundo enriquecimiento, una programación en lenguaje XSLT (Allés Torrent, 2015: 20-21) permite extraer la información relativa a la cantidad, el origen y el destino de estas relaciones de cada texto con la obra de Góngora. Este protocolo permite calcular idénticos resultados de forma sistemática, produciendo así una lectura controlada de las relaciones intertextuales de la polémica con el poeta: un registro cuantitativo que, llegado el caso, puede ser repetido por cualquier investigador (Lemercier y Zalc, 2008: 48-51). Por descontado, el mismo protocolo resulta válido y está siendo aplicado a las relaciones de los textos polémicos unos con otros.

Con estos datos intertextuales nos es posible construir, mediante programas de análisis de redes, un gráfico de la red cerrada polémica-Góngora. Los nodos corresponden a cada uno de los textos; las relaciones, orientadas y específicas para cada uno de ellos, parten del nodo polémico hacia el nodo-poema o hacia otro nodo polémico. Así, cada gráfico individual es homogéneo con el gráfico del conjunto: a las relaciones que parten del primer texto se suman las del segundo, y así sucesivamente. Con un programa como Gephi, el resultado es un gráfico dinámico en el que la datación de los textos permite crear una animación del sistema intertextual de la polémica. El resultado tiene equivalentes en otros proyectos del laboratorio OBVIL de la Université Paris Sorbonne, como el proyecto Molière ${ }^{24}$ en el que un gráfico con las relaciones de los personajes en el escenario constituye la portada de cada comedia ${ }^{25}$.

El resultado obtenido constituye, por tanto, un mapa del hipertexto (en el sentido intertextual) de la polémica en función de sus relaciones con el hipotexto gongorino o polémico. Este mapa tendrá un hipervínculo en cada nodo para construir un hipertexto (en el sentido digital) en forma de gráfico de la polémica gongorina. De esta manera, constituirá una

\footnotetext{
${ }^{24}$ Accesible desde http://obvil.paris-sorbonne.fr/projets/projet-moliere.

25 Accesible desde, por ejemplo, la edición de Dom Juan ou le Festin de Pierre, en http://obvil.parissorbonne.fr/corpus/moliere/moliere dom-juan. Una exposición de la metodología empleada para el desarrollo de este gráfico se encuentra disponible en línea (Glorieux, 2016).
} 
tabla de materias visual y dinámica: un mapa de la polémica. En Gephi el cursor permite resaltar la red de relaciones en torno a un nodo: el lector que quiera observar la red intertextual construida a partir de un poema de Góngora o de una pieza de la polémica podrá observar intuitivamente los textos que la componen y acceder a ellos directamente, con un simple clic.

La construcción de un hipertexto visual e intuitivo de la polémica gongorina tendrá notables consecuencias en la lectura de este corpus. Volviendo a la cita inicial de Alexandra Saemmer, hemos de considerar el hipervínculo como parte de las características de un hipertexto:

El hipervínculo, como texto que debe ser manipulado, con el clic o con otros gestos de carácter potencialmente icónico que deben ser analizados en relación con los signos alfabéticos; la animación textual, que apela a otra forma de iconicidad basada en el movimiento; la relación texto-imagen, en la página-pantalla o entre las páginaspantalla (Saemmer, 2015: 648),

Avanzamos a continuación una serie de hipótesis sobre la lectura de la polémica con este gráfico intertextual considerado como un hipertexto, por ser una tabla de materias con hipervínculos.

Ante todo, la relación entre texto e imagen es fundamental con este instrumento. El gráfico es producto de una lectura controlada (Lemercier y Zalc, 2008: 49) de los textos editados a partir del enriquecimiento XML y de su análisis con XSLT: la imagen nace del texto. A la inversa, pese a su carácter icónico, el gráfico tiene un horizonte textual, basado en el hipervínculo. De esta manera, la relación texto-imagen toma aquí la forma de un ir y venir que corresponde a una de las virtudes heurísticas de la intermedialidad como método: "esta lógica del ir y venir consiste en comparar el rendimiento de un concepto en un medium para, a continuación, probar el resultado obtenido en otro" (Jost, 2005: 113) ${ }^{26}$. Pensemos, por ejemplo, en conceptos fundamentales del análisis de gráficos como la centralidad de los actores de una red: estudiar este concepto en el medium del gráfico -como forma matemática y no como simple imagen- puede contribuir en el estudio de la polémica a:

Afinar la cronología (...) distinguiendo estas etapas en torno a nudos conflictivos, como comenzó a hacerlo Roses en su libro, y como hace el libro reciente de María José Osuna, aislando una fase primeriza de la recepción de las Soledades (Blanco, 2012: 63).

Ahora bien, en lo que se refiere a las metamorfosis del libro (Souchier, 2013: 35) un gráfico de estas características constituye un argumento a favor de la lectura en la web. De esta manera, como avanza Marc Jahjah, también en el campo científico "entender mejor la

\footnotetext{
${ }^{26}$ En el texto original, "Cette logique de l'aller-retour consiste à comparer le fonctionnement d'un concept dans un média pour, ensuite, tester les résultats acquis dans un autre" (traducción propia).
} 
edición supone por tanto mejorar la Web y desarrollar estándares (editoriales) para la Web" (2015: 701) $)^{27}$.

Sobre estas bases, el empleo de este gráfico como tabla de materias permite imaginar formas intuitivas para leer a Góngora, explorando de manera distante el corpus de su recepción coetánea que tanto ha aportado a los estudios gongorinos (Blanco, 2013: 7-40). E lector podrá orientar su lectura en función de una red, como ya ocurre en las redes sociales, donde "los intermediarios cambian la orientación de los contenidos y de esta manera cambian también la lectura en si" (Boullier, 2011: 4) ${ }^{28}$. Al resaltar las relaciones intertextuales directas de cada testimonio, un gráfico de estas características lleva a lo que Dominique Boullier llama una lectura de exploración. Una lectura que permite que el lector explore y componga el texto que le interesa:

\begin{abstract}
$Y$ es que explorar no es otra cosa que recomponer un recorrido que puede parecer oportunista, guiado únicamente por aquello que destaca [...] A partir de esos recorridos nacen por tanto documentos enriquecidos, heterogéneos, para los cuales una nueva categoría de lectura debe ser creada, y el término de "lectura de exploración" nos parece el más adecuado (Boullier, 2011: 9-10) ${ }^{29}$.
\end{abstract}

Tal lectura de exploración contará también con otras coordenadas visuales como, por ejemplo, un valor cromático establecido en función del posicionamiento a favor o en contra de Góngora de los textos de la polémica.

\title{
4. CONCLUSIÓN
}

La edición digital de un corpus tan interconectado como el de la polémica gongorina junto con la Obra completa del cordobés, constituye un desafío editorial y teórico para la Filología tradicional. El instrumento del hipervínculo y la construcción de hipertextos digitales, en varias escalas, permiten afrontarlo respondiendo a las aspiraciones más ambiciosas de la crítica gongorina reciente. La codificación XML de textos interconectados permite la inscripción de hipervínculos en la secuencia textual, convirtiendo las ediciones en hipertextos navegables y facilitando la lectura convergente de Góngora con su recepción coetánea.

\footnotetext{
${ }^{27}$ En el texto original, "Mieux comprendre l'édition, c'est donc améliorer le Web et développer des standards pour le Web" (traducción propia). Sobre la lectura en línea accesible desde Jahjah (2015: 700-702).

${ }^{28}$ En el texto original, "Les médiations de la lecture et les médiateurs changent l'orientation dans les contenus; ce faisant, ils changent aussi la lecture elle-même" (traducción propia).

${ }^{29}$ En el texto original, "Car explorer, c'est en fait recomposer un parcours qui peut paraitre opportuniste, guidé seulement par les saillances" y "De ces parcours naissent alors des documents augmentés, hétérogènes, pour lesquels une nouvelle catégorie de lecture doit être produite, et le terme de 'lecture d'exploration' parait le plus adapté" (traducción propia). Más adelante, Boullier (2011: 11) comenta los instrumentos de navegación adecuados para una lectura de estas características, entre los cuales ocupan el primer lugar el mapa y la exploración de gráficos.
} 
La construcción de un hipertexto de la polémica nos lleva a presentar tres propuestas de tablas de materias para las publicaciones del proyecto. La primera, para la obra de Góngora, toma la forma de un índice hipertextual y dinámico en el que el lector elige cómo clasificar la obra del poeta para orientarse en ella en función del primer verso, del título del poema o de la fecha de composición. Este instrumento se encuentra ya en línea y es plenamente operativo. El segundo índice de la poesía de Góngora, actualmente en desarrollo, tomará la forma de una ontología (Rastier, 2004: 15-40) que remita a los versos del poeta a partir de las palabras más significativas en términos cuantitativos dentro de su corpus íntegro. Ambos índices contarán con hipervínculos que permitan al lector alcanzar con un simple clic el texto o el lugar que les interesa en las publicaciones del proyecto. La tercera propuesta se aplica al conjunto de las publicaciones del proyecto Góngora, la polémica junto con la obra del poeta, y es objeto de un trabajo en desarrollo del que hemos expuesto las bases metodológicas y los objetivos teóricos, basados en el análisis de redes. El objetivo es construir un gráfico hipertextual que documente como un mapa las relaciones intertextuales directas de cada texto publicado en el repositorio del OBVIL ${ }^{30}$.

Estos tres hipertextos de la polémica y de la obra de Góngora se basan en el marcado $\mathrm{XML}$ de las ediciones digitales de ambos corpus que el proyecto publica en línea, de forma gratuita, bajo una licencia Creative Commons y en formato HTML, EPUB, TXT y TEI. EI resultado es un instrumento multimedia para releer a Góngora y a sus primeros lectores que aporta, gracias a las Humanidades Digitales, nuevos enfoques y nuevas metodologías para el estudio de un debate central en la historia de la literatura áurea. Un debate que, al requerir la implementación de modelos concretos de etiquetado XML, la construcción de hipervínculos e hipertextos en varias escalas y el desarrollo de una metodología capaz de compaginar la Filología tradicional y las Humanidades Digitales, pretende ser un laboratorio para:

Escaparnos, a la vez, de un nuevo cientificismo que pretende hacer tabula rasa de las ciencias humanas tal y como el siglo XX las ha construido y de una fe cándida en el poder de los algoritmos, pero todo ello dando el lugar que se merecen a las nuevas tecnologías del texto y del conocimiento (Gefen, 2015: 612) ${ }^{31}$.

Compaginando la tradición filológica y la revolución digital, esperamos leer el texto gongorino con ojos siempre más conscientes, si no nuevos.

\footnotetext{
${ }^{30}$ Las dos tablas de materias hipertextuales en desarrollo se publicarán en breve plazo en el sitio web del proyecto en el Labex OBVIL. Accesible desde http://obvil.paris-sorbonne.fr/corpus/gongora/.

${ }^{31}$ En el texto original, "Échapper à la fois à un nouveau scientisme qui voudrait faire table rase des sciences humaines telles que le $X X^{e}$ siècle les a construites et à une foi candide dans le pouvoir des algorithmes, tout en faisant une juste place à ces nouvelles technologies du texte et du savoir" (traducción propia).
} 


\section{REFERENCIAS BIBLIOGRÁFICAS}

ALLÉS TORRENT, S. (2015). “Edición digital y algunas tecnologías aliadas”. Ínsula, 822, 1821.

ALONSO, D. (1982). "Todos contra Pellicer". En Estudios y ensayos gongorinos, 462-487. Madrid: Gredos.

BARIL, E. y GARNIER, B. (2015). Utilisation d'un outil de statistiques textuelles. IRaMuTeQ 0.7 alpha 2 Interface de $R$ pour les Analyses Multidimensionnelles de Textes et de Questionnaires. IRaMuTeQ.org, Documentation. Recuperado de http://www.IRaMuTeQ.org/documentation/fichiers/Pas\%20a\%20Pas\%20IRAMUTEQ 0.7alpha2.pdf el 14/02/2017.

BERRA, A. (2015). "Pour une histoire des humanités numériques". Critique, 819-820 (Des chiffres et des lettres. Les Humanités Numériques), 613-626.

BLANCO, M. (2010). "Góngora et la querelle de I'hyperbate". Bulletin hispanique, 112.1, 169207. Recuperado de http://bulletinhispanique.revues.org/1128 el 14/02/2017. (2012). "La polémica en torno a Góngora (1613-1630). El nacimiento de una nueva conciencia literaria”. Mélanges de la Casa de Velázquez, 42.1, 49-70. Recuperado de https://mcv.revues.org/4255 el 14/02/2017.

(2013). "Las Soledades a la luz de la polémica". En España e Italia en tiempos de Góngora, B. Capllonch, S. Pezzini, G. Poggi y J. Ponce Cárdenas (eds.), 7-40. Pisa: Edizioni E.T.S.

(ed.) (2016). Discurso poético de don Juan de Jáuregui. París: OBVIL. Recuperado de http://obvil.paris-sorbonne.fr/corpus/gongora/1624 discurso-poetico/ el 14/02/2017.

BOULLIER, D. (2011). "Profils, alerte et vidéo: de l'outre-lecture à la fin de la lecture?". En Pour une sociologie de la lecture, C. Evans (ed.), 41-58. París: Cercle de la Librairie. Recuperado de https://hal.archives-ouvertes.fr/hal-01044428/document el 14/02/2017. CARREIRA, A. (1998). Gongoremas. Barcelona: Península.

(ed.) (2000). Luis de Góngora, Obras completas. Madrid: Fundación José Antonio de Castro.

(ed.) (2016). Góngora. Poesía. París: OBVIL. Recuperado de http://obvil.parissorbonne.fr/corpus/gongora/gongora obra-poetica/ el 14/02/2017.

CARREÑO, A. (ed.) (2010). Lope de Vega. El Castigo sin venganza. Madrid: Cátedra.

CASTILLO SOLÓRZANO, A. (2015). El culto graduado de Alonso de Castillo Solórzano, R. Bonilla Cerezo (ed.). París: OBVIL. Recuperado de http://OBVIL.parissorbonne.fr/corpus/gongora/1625 el-culto-graduado/ el 08/02/2017. 
CUMMINGS, J. (2007). "The Text Encoding Initiative and the Study of Literature". En A Companion to Digital Literary Studies, R. Siemens y S. Schreibman (eds.), 451-476. Oxford: Blackwell.

DAMIAN-GRINT, P. (2007). "Eighteenth-Century Literature in English and Other Languages". En A Companion to Digital Literary Studies, R. Siemens y S. Schreibman (eds.), 106120. Oxford: Blackwell.

ELVIRA, M. (ed.) (2015). Francisco Fernández de Córdoba. Parecer de don Francisco de Córdoba acerca de las Soledades, a instancia de su autor. París: OBVIL. Recuperado de http://OBVIL.paris-sorbonne.fr/corpus/gongora/1614 parecer/ el 08/02/2017.

GANASCIA, J.G. (2015). "Les big data dans les humanités". Critique, 819-820 (Des chiffres et des lettres. Les humanités numériques), 627-636.

GEFEN, A. (2015). "Présentation", Critique, 819-820 (Des chiffres et des lettres. Les humanités numériques), 611-612.

GENETTE, G. (1982). Palimpsestes. La littérature au second degré. París: Seuil.

GLORIEUX, F. (2015). Le traitement de textes (odt) pour produire des documents structurés $(X M L / T E I)$ - Odette. Francia: Catalogue d'Hypothèses. Recuperado de http://resultats.hypotheses.org/267 el 14/02/2017.

(2016). Dramagraphie (sur le Pamphlet 6 de Franco Moretti). Francia: Catalogue d'Hypothèses. Recuperado de http://resultats.hypotheses.org/644 el 14/02/2017.

GLORIEUX, F. y JOLIVET, V. (2015). Teibook. París: OBVIL. Recuperado de https://oeuvres.github.io/Teinte/teinte.html el 08/02/2017.

GONZÁLEZ BOIXO, J.C. (ed.) (1997). Espinosa Medrano, Juan de [El Lunarejo] Apologético en favor de don Luis de Góngora (1662). Roma: Bulzoni.

HEYMANN, S. (2014). "Gephi”. En Encyclopedia of Social Networks and Mining, R. Alhajj y J. Rokne (eds.), 612-625. Nueva York: Springer-Verlag.

JAHJAH, M. (2015). "Protée ou les mutations du livre". Critique, 819-820 (Des chiffres et des lettres. Les Humanités Numériques), 693-703.

JAMMES, R. (1994). "La polémica de las Soledades (1613-1666)". En Luis de Góngora. Soledades, 607-719. Madrid: Castalia.

JOST, F. (2005). "Des vertus heuristiques de l'intermédialité". Intermédialités: histoire et théorie des arts, des lettres et des techniques/Intermediality: History and Theory of the Arts, Literature and Technologies, 6, 109-119.

LAURENT, B. y MERCKLÉ, P. (2011). "Analyse des réseaux: une introduction à Pajek". Quanti. Recuperado de http://quanti.hypotheses.org/512 el 14/02/2017.

LEMERCIER, C. y ZALC, C. (2008). Méthodes quantitatives pour I'historien. París: La Découverte. 
LÓPEZ BUENO, B. (2013a). "Góngora apologizado. A propósito de las décimas 'Por la estafeta he sabido"'. En Góngora y el epigrama. Estudios sobre las décimas, J. Matas Caballero, J.M. Micó, J. Ponce Cárdenas (eds.), 123-142. Madrid: Iberoamericana Vervuert.

(2013b). "De nuevo ante el soneto 'Restituye a tu mudo horror divino': el texto en su verdadero contexto". Bulletin hispanique, 115.2, 724-748.

McGANN, J.J. (2001). Radiant Textuality: Literature after the World Wide Web. Nueva York: Palgrave.

MORETTI, F. (2005). La letteratura vista da Iontano. Turín: Einaudi.

PELLICER, J. (1630). Lecciones solemnes a las obras de don Luis de Góngora y Argote, Madrid: Imprenta del Reino. Recuperado de https://books.google.fr/books?id=sWLIG p4YNsC\&printsec=frontcover\&hl=es\&source =gbs ge summary $r \& c a d=0-v=$ onepage $\& q \& f=$ false el 14/02/2017.

(1971). Lecciones solemnes a las obras de don Luis de Góngora y Argote. Nueva YorkHildesheim: Georg Olms Verlag (reimpresión facsímil de la edición de Madrid de 1630). PERIÑÁN, B. (1976). “El 'león prodigioso' y una raposa anticulterana: crítica literaria en el siglo XVII". Studi Ispanici, III, 153-186. Recuperado de http://www.cervantesvirtual.com/descargaPdf/el-leon-prodigioso-y-una-raposaanticulterana--critica-literaria-en-el-siglo-xvii/ el 14/02/2017.

PONCE CÁRDENAS, J. (2014). "Manuel Serrano de Paz: deslindes para un perfil biográfico y crítico". e-Spania, 18. Recuperado de http://e-spania.revues.org/23607 el 08/02/2017.

RASTIER, F. (2004). "Ontologie(s)". Revue des sciences et technologies de l'information, 18.1, $15-40$.

ROJAS CASTRO, A. (2015). "De los datos al metamedio". Ínsula, 822, 15-17.

ROSES LOZANO, J. (1994). Una poética de la oscuridad. La recepción crítica de las Soledades en el siglo XVII. Madrid-Londres: Tamesis. (2007). Góngora: “Soledades” habitadas. Málaga: Universidad de Málaga.

SAEMMER, A. (2015). "Hypertexte et narrativité". Critique, 819-820 (Des chiffres et des lettres. Les Humanités Numériques), 637-652.

SALAZAR MARDONES, C. (1636). Ilustración y defensa de la Fábula de Piramo y Tisbe compuesta por D. Luis de Góngora y Argote, Capellán de su Magestad y Racionero de la Santa Yglesia de Cordova. Madrid: Imprenta Real. Edición digital en prensa en el OBVIL a cargo de Sara Pezzini. Recuperado de http://babel.hathitrust.org/cgi/pt?id=ucm.5320769638 el 08/02/2017.

SALCEDO CORONEL, G. (1644). Segundo tomo de las Obras de Don Luis de Gongora comentadas por D. Garcia de Salzedo. Madrid: por Diego Díaz de la Carrera, a costa 
de

Laso.

Recuperado

de

http://bvpb.mcu.es/es/consulta/registro.cmd?id=451252 el 14/02/2017.

SALINAS, P. (2007). “La realidad y el poeta en la poesía española”. Obras completas de Pedro Salinas, II (Ensayos completos), 405-497. Madrid: Cátedra.

SÁNCHEZ ROBAYNA, A. (2012). "La recepción de Góngora en Europa y su estela en América". En Góngora, la estrella inextinguible, J. Roses Lozano y S. Urraca (eds.), 171-189. Madrid: Biblioteca Nacional de España.

SOUCHIER, E. (2013). “Livre numérique ou écrit de réseau ?". En La grande aventure du livreL'histoire du livre, de la tablette d'argile à la tablette, A. Zali (ed.), 34-39. París: Bibliothèque Nationale de France.

WASSERMAN, S. y FAUST, K. (1994). Social Network Analysis: Methods and Applications. Cambridge: Cambridge University Press.

WHITE, D. y GILMAN McCANN, H. (1988). "Cities and Fights: Material Entailment Analysis of the Eighteenth-Century Chemical Revolution". En Social Structures: A Network Approach, B. Wellman y S. Berkowitz (dirs.), 380-399. Cambridge: Cambridge University Press. 